\title{
cmaJOPEN
}

\section{Attitudes toward medical cannabis among family physicians practising in Ontario, Canada: a qualitative research study}

\author{
Jeremy Y. Ng MSc, Kevin Gilotra, Sana Usman BSc, Yaping Chang PhD, Jason W. Busse DC PhD
}

Abstract

Background: Medical cannabis has been legally available in Canada since 2001, but its benefits and harms remain uncertain. We explored attitudes toward medical cannabis among family physicians practising in Ontario.

Methods: Between January and October 2019, we conducted a qualitative study of Ontario family physicians using semistructured telephone interviews. We applied thematic analysis to interview transcripts and identified representative quotes.

Results: Eleven physicians agreed to be interviewed, and 3 themes regarding medical cannabis emerged: reluctance to authorize use, concern over harms and lack of practical knowledge. Participants raised concerns about the limited evidence for, and their lack of education regarding, the therapeutic use of cannabis, particularly the harms associated with neurocognitive development, exacerbation of mental illness and drug interactions in older adults. Some participants thought medical cannabis was overly accessible and questioned their role following legalization of recreational cannabis.

Interpretation: Despite the increasing availability of medical cannabis, family physicians expressed reluctance to authorize its use because of lack of knowledge and concerns regarding harms. Family physicians may benefit from guidance and education that address concerns they have surrounding medical cannabis.

annabis has been legally available for select medical conditions in Canada since 2001. ${ }^{1}$ Until recently, however, regulations made access to medical cannabis difficult, limiting its use by patients. On Oct. 17, 2018, the Cannabis Act came into effect, legalizing the sale and use of recreational cannabis across Canada. ${ }^{2}$ Licensed health care practitioners can provide authorization for patients to acquire medical cannabis, who can then register with Health Canada to produce a limited amount of cannabis for personal use, designate another individual to produce their medical cannabis or acquire cannabis for medical purposes through a licensed producer. ${ }^{3}$

The number of Canadians authorized to use medical cannabis increased from 23930 in June 2015 to 377024 by September $2020 .^{4}$ The increased use of medical cannabis was likely the result of the easing of regulations, ${ }^{5-7}$ greater availability given the growing numbers of producers and cannabis clinics $^{8-10}$ and reduced stigma around the use of cannabis for therapeutic purposes. ${ }^{11-14}$ One online patient resource now lists 100 medical cannabis clinics in Ontario alone. ${ }^{15}$

Market data from 2017 to 2019 show that Ontario ranks the highest among all provinces with respect to the amount of medical cannabis sold to clients and the total number of client registrations. ${ }^{16}$ Patients increasingly seek guidance from physicians regarding the benefits and harms of therapeutic cannabis; however, physicians receive minimal education on cannabis use during their training. Moreover, the evidence for medical cannabis is limited and often conflicting. ${ }^{17,18}$ For example, the most common indication for medical cannabis is chronic pain. ${ }^{19}$ The National Academies of Sciences, Engineering, and Medicine concluded that patients treated with cannabis are more likely to have a clinically significant reduction in pain symptoms, ${ }^{19}$ but the National Institute for Health Care and Excellence has made a strong recommendation against the use of cannabis for chronic pain. ${ }^{20}$ In 2019, the Canadian Medical Association issued its policy on medical marijuana, stating that although cannabis may offer patients relief when conventional therapies fail, a lack of evidence surrounding the risks and benefits of its use makes it difficult for physicians to advise patients properly. ${ }^{21}$ The purpose of this qualitative study was to investigate attitudes toward medical cannabis among family physicians practising in Ontario.

\section{Competing interests: None declared.}

This article has been peer reviewed.

Correspondence to: Jason Busse, bussejw@mcmaster.ca

CMAJ Open 2021. DOI:10.9778/cmajo.20200187 


\section{Methods}

\section{Study design}

We conducted a descriptive qualitative research study ${ }^{22}$ and used thematic analysis ${ }^{23}$ to explore attitudes toward medical cannabis among family physicians. We followed the consolidated criteria for reporting qualitative research (COREQ) checklist in reporting our findings. ${ }^{24}$

\section{Participants}

We recruited family physicians practising in Ontario, Canada, between January and October 2019. We acquired our participants through snowball sampling. ${ }^{25}$ One author (J.W.B.) reached out to a family physician to provide contact information of colleagues who held variable views toward medical cannabis. We then asked participating physicians for contact information of colleagues we could approach to interview. This continued until we interviewed enough physicians to achieve saturation of themes and subthemes on perspectives regarding medical cannabis. ${ }^{26}$ Before being interviewed, each participant was sent an information letter and a consent form outlining the purpose of the study and how confidentiality would be maintained.

\section{Data collection}

We interviewed participants using an interview guide with open-ended questions (Appendix 1, available at www.cmajopen. ca/content/9/2/E342/suppl/DC1). We developed and tested our guide in accordance with McGrath and colleagues' method, which provides 12 recommendations for conducting qualitative research interviews (Appendix 2, available at www.cmajopen.ca/ content/9/2/E342/suppl/DC1). ${ }^{27}$ Furthermore, we consulted qualitative studies on related topics to inform our interview guide $^{28-31}$ and engaged a family physician to review our interview guide for clarity and completeness.

For each participant, we collected demographic information including sex, age, specialization, years of practice, location of medical school training, location of residency training and site of practice (urban or rural). We also asked participants to state whether they authorized or prescribed medical cannabis.

Three authors (J.Y.N., K.G. or S.U.) conducted phone interviews with participants after they provided their informed consent to be interviewed. All interviews were audio recorded. The lead author (J.Y.N.) has training in qualitative interviewing and provided supervision and training to K.G. and S.U. We stopped recruitment when 3 members of our team (J.Y.N., Y.C. and J.W.B.) agreed that saturation of themes had been achieved. We did not return transcripts to participants, nor did we conduct follow-up interviews. Two authors (K.G. and S.U.) transcribed all interviews verbatim. We ensured participant anonymity by replacing names with an identification number in all transcribed documents and interview notes.

\section{Data analysis}

We analyzed all interview data by applying inductive thematic analysis, which has been shown to be effective in investigating and describing a range of experiences. ${ }^{32} \mathrm{We}$ adopted a realist approach whereby we assumed that participants would report truthfully about their beliefs and attitudes. ${ }^{33}$

Two team members (J.Y.N. and Y.C.) read the interview transcripts and notes several times. Next, the same team members coded and aggregated transcribed text into meaningful themes and subthemes, and labelled constructs. We used an open coding process to establish the primary categories of information from each transcript, independently and in duplicate, and then connected the categories to derive main themes and subthemes. We resolved disagreements by discussion. Based on the codes generated from the analysis, the same 2 reviewers generated a set of theoretical propositions, independently and in duplicate, and achieved consensus. Lastly, all team members reviewed the results and confirmed the main themes and subthemes of our study findings, which were accompanied by supporting quotes. We used both manual coding and NVivo 12 software (QSR International).

\section{Ethics approval}

The Hamilton Integrated Research Ethics Board approved our study (project no. 5458).

\section{Results}

We contacted a total of 21 family physicians with the intention to stop recruitment once data saturation was achieved; 8 declined to participate, and 2 were found to be ineligible as they were not actively practising. The remaining 11 agreed to participate in our study. Our participants included 6 men and 5 women, who had been in practice for a median of 3.5 (range 1-33) years. Eight attended medical school in Canada, 3 abroad; all had completed their family medicine residency in Canada. One participant held additional specialization in public health and preventive medicine (Table 1). The interview time was about 30 minutes. We reached saturation after interviewing 11 physicians.

\section{Main themes}

We identified 3 main themes: reluctance to authorize medical cannabis, concern over harms associated with medical cannabis and lack of knowledge surrounding administration of medical cannabis. Each theme contained 4 subthemes; participant quotes supporting thematic analysis are shown in Table 2.

\section{Reluctance to authorize medical cannabis}

For the main theme "reluctance to authorize medical cannabis," there were 4 subthemes: lack of evidence, indications for therapeutic use, discomfort with therapeutic use and openness to emerging evidence.

\section{Lack of evidence}

Eight physicians felt the evidence supporting the use of cannabis for medical purposes was limited. Specifically, they perceived that clinical trials were often poorly designed, followed patients for short time periods and did not inform long-term effects; benefits in trials showing statistical significance were typically modest. Two physicians felt more 


\begin{tabular}{|c|c|}
\hline Characteristic & $\begin{array}{c}\text { No. }(\%) \text { of } \\
\text { participants } \\
n=11\end{array}$ \\
\hline \multicolumn{2}{|l|}{ Gender } \\
\hline Male & $6(54)$ \\
\hline Female & $5(46)$ \\
\hline Age, median (range), yr & $32(27-74)$ \\
\hline \multicolumn{2}{|l|}{ Specialization } \\
\hline Family medicine only & $10(90)$ \\
\hline $\begin{array}{l}\text { Family medicine and public } \\
\text { health/preventive medicine }\end{array}$ & $1(10)$ \\
\hline Years in practice, median (range) & $3.5(1-33)$ \\
\hline \multicolumn{2}{|l|}{ Location of medical school training } \\
\hline Canada & $8(73)$ \\
\hline Abroad $†$ & $3(27)$ \\
\hline \multicolumn{2}{|l|}{ Location of residency training } \\
\hline Canada & $11(100)$ \\
\hline Abroad & $0(0)$ \\
\hline \multicolumn{2}{|l|}{ Location of medical practice } \\
\hline Urban & $11(100)$ \\
\hline Rural & $0(0)$ \\
\hline \multicolumn{2}{|l|}{ Authorizes or prescribes cannabis } \\
\hline Yes & $4(36)$ \\
\hline No & $7(64)$ \\
\hline $\begin{array}{l}\text { *Unless indicated otherwise. } \\
\text { †Two physicians attended medical school } \\
\text { medical school in the United States. }\end{array}$ & and 1 attended \\
\hline
\end{tabular}

research on effectiveness was needed before cannabis should be offered to patients. Participants noted evidence gaps regarding cannabis harms among certain populations (i.e., children, emerging adults and older adults), the effects of cannabis on the ability to drive and whether the net benefit-to-harm ratio was favourable for management of mental illness (e.g., posttraumatic stress disorder, anxiety).

\section{Indications for therapeutic use}

All participants thought that cannabis could be helpful for managing chronic pain, particularly neuropathic pain. Some physicians perceived a therapeutic role for cannabis in the treatment of anxiety, insomnia or muscle spasticity associated with multiple sclerosis, as well as for relief from chemotherapy-induced nausea and vomiting and for appetite stimulation. None of the participating physicians chose medical cannabis as the first line of treatment for any condition, and considered it only after other treatment options had failed or by patient request.

\section{Discomfort with therapeutic use of cannabis}

Six physicians avoided authorizing medical cannabis altogether, and 2 prescribed synthetic cannabis (i.e., nabilone).
Physicians who supported the therapeutic use of cannabis reported insufficient knowledge regarding what cannabis type to use, and how to pursue dosing and optimal monitoring; they preferred instead to refer patients to colleagues with an interest in cannabis.

\section{Openness to emerging evidence}

Despite the perceived lack of evidence and reluctance to authorize medical cannabis, 3 participants noted it was important to keep an open mind. They were willing to consider that cannabis may have a role in health care, acknowledged that patients were increasingly asking about medical cannabis and were aware of the need to address their own biases when engaging in discussions.

\section{Harms associated with the use of cannabis}

There were 4 subthemes, effect on neurocognitive development, harms in older adults, exacerbation of mental illness and concerns regarding cannabis clinics, in the main theme "harms associated with the use of cannabis."

\section{Effect on neurocognitive development}

Four physicians raised concerns about the effect of cannabis on neurocognitive development and queried whether cannabis use among adolescents and young adults may predispose them to mental illness. Some physicians felt that setting the legal age for use of recreational cannabis at 18 years may give the impression that therapeutic use was safe at this age.

\section{Harms for older adults}

Two physicians raised concerns about cannabis use among older adults, including the potential for drug interactions given the common occurrence of polypharmacy in this population. They also raised concerns regarding adverse events associated with cannabis use, such as dizziness and sedation, and how this may affect older patients' quality of life, ability to drive and capacity to care for themselves.

\section{Exacerbation of mental illness}

Three physicians expressed concern over the impact of cannabis use on people with preexisting, or at high risk for, mental illness. Participants noted that cannabis use may exacerbate patients' symptoms of depression and anxiety or interfere with sleep, and acknowledged evidence to implicate cannabis use in early-onset psychosis among emerging adults.

\section{Concerns regarding cannabis clinics}

Although physicians largely referred patients who were interested in pursuing medical cannabis to practices that focused on this therapy, 3 participants raised concerns about the quality of care provided through cannabis clinics. Participants perceived that very few interested patients were denied cannabis, and that most patients were not provided with a detailed explanation of possible harms. One physician highlighted their experience that patients with comorbid mental illnesses, including substance use disorders, found it easy to access medical cannabis though these clinics. 


\section{Knowledge about medical cannabis}

For the theme "knowledge about medical cannabis," 4 subthemes emerged during data analysis: inadequate training, continuing education, the physician's role regarding medical cannabis and recreational versus medical cannabis.

\section{Inadequate training}

Five physicians described their knowledge of medical cannabis as insufficient in regard to clinical indications, dosing or monitoring. Older physicians were not exposed to information on medical cannabis in medical school or residency; more recent graduates received some lectures on medical cannabis, but were not well versed on the topic. Our participants thought that acquiring training in the use of medical cannabis required them to seek out online courses and conferences.

\section{Continuing education}

Nine physicians expressed an interest in receiving education regarding medical cannabis. When asked what kind of training or education they wished to receive, answers were mixed and often related to their patient population. Some physicians expressed an interest in general topics, such as clinical indications for cannabis and dosing.

Table 2 (part 1 of 2): Participant quotes supporting thematic analysis

\begin{tabular}{|c|c|}
\hline Theme/subtheme & Representative quote(s) \\
\hline \multicolumn{2}{|c|}{ Reluctance to authorize medical cannabis } \\
\hline Lack of evidence & $\begin{array}{l}\text { I don't think most of the results of studies are that strong, they're not really well-designed studies for the most } \\
\text { part ... . (MC001) } \\
\text {... some studies show that it's really effective and some studies show that it's not very effective. I suspect } \\
\text { we've reached the point where we're probably a little too liberal for the conditions we prescribe it for. (MC009) }\end{array}$ \\
\hline $\begin{array}{l}\text { Indications for } \\
\text { therapeutic use }\end{array}$ & $\begin{array}{l}\text { It's an okay adjunct, but it wouldn't be my first line for pain control at all. (MC002) } \\
\ldots \text { it's more of a second- or third-line treatment ... certain patients will find it helpful. (MC004) } \\
\text { There's very few things, if any, that I would go to medical cannabis as my first medication to treat. (MC008) }\end{array}$ \\
\hline $\begin{array}{l}\text { Discomfort with } \\
\text { therapeutic use of } \\
\text { cannabis }\end{array}$ & $\begin{array}{l}\text { I'm not } 100 \% \text { comfortable prescribing it, I do feel it might be helpful for some conditions, but l'm just not sure } \\
\text { of the entire process of how to go about prescribing it and monitoring its use. (MC001) } \\
\text { I don't prescribe it at all, I usually refer it out to clinics who are specialized in that. (MC002) } \\
\text { I would be happy if it went away, in terms of [the] physician's responsibility toward it. I do not want to be } \\
\text { prescribing marijuana. (MC006) }\end{array}$ \\
\hline $\begin{array}{l}\text { Openness to emerging } \\
\text { evidence }\end{array}$ & $\begin{array}{l}\text { I think you have to keep an open mind, and you have to be attuned to what your patients are telling you ... if } \\
\text { you're not willing to listen to what patients are telling you about what they're using, and you don't present an } \\
\text { unbiased front, then people aren't going to tell you what they're doing. (MC009) } \\
\text { I think that we need to make sure we are providing our patients with access to evidence-based treatment and } \\
\text { addressing any financial barriers and any stigma that may exist around particular treatments. I think we need } \\
\text { to be careful of that when we are thinking about prescribing medical marijuana. (MC011) }\end{array}$ \\
\hline \multicolumn{2}{|c|}{ Harms associated with the use of cannabis } \\
\hline $\begin{array}{l}\text { Effect on } \\
\text { neurocognitive } \\
\text { development }\end{array}$ & $\begin{array}{l}\text { There is so much research saying that the brain is still changing and the reality is we don't know what } \\
\text { happens to kids' brains when they take marijuana at the age of } 15 \text {. And you know, I have so many patients } \\
\text { who are young, who are like, "oh well now that is legalized for the age of } 18 \text {, [and] I'm } 14 \text { and I'm so close, I'm } \\
\text { sure it is fine." And I think the fact that legalization, especially at such a young age, gives the message to a lot } \\
\text { of people that it's safe. (MC010) }\end{array}$ \\
\hline Harms for older adults & $\begin{array}{l}\text { Maybe sort of looking at long-term effects on older people. All the medications we prescribe, there are certain } \\
\text { geriatric populations that take various medications so I just want to know if there's anything in particular or } \\
\text { things to watch for. (MC002) } \\
\text { What is the effect of adding a cannabis product into a geriatric population that tends to be already medically } \\
\text { more complex and already on lots of other medications and have multiple comorbidities? So, what impact } \\
\text { does that have potentially, on their quality of life, ability to continue to drive a car, ability to continue to take } \\
\text { care of themselves, and maybe dependence issues. (MC009) }\end{array}$ \\
\hline $\begin{array}{l}\text { Exacerbation of mental } \\
\text { illness }\end{array}$ & $\begin{array}{l}\text { Our patients have mental health issues, ranging from depression to anxiety to schizophrenia, and you know, } \\
\text { you worry about harms for people especially for people who have [mental] illnesses. (MC006) } \\
\text { So some of the [symptoms] l've noticed so far have been an increase in anxiety, difficulty with sleep, even } \\
\text { cases of potential psychosis. (MC007) }\end{array}$ \\
\hline $\begin{array}{l}\text { Concerns regarding } \\
\text { cannabis clinics }\end{array}$ & $\begin{array}{l}\text { Cannabis clinics are fairly easy to access for most of these [patients]. (MC004) } \\
\text { I would, for the most part, send patients to marijuana [clinics]; there are a couple in Hamilton. Everyone } \\
\text { wound up getting it. Most people that did had addiction issues and mental health issues. (MC006) } \\
\text { I've had patients who've come in and were prescribed medical cannabis and I would be like "oh you are so } \\
\text { young, did the people go through the risks with you?" and they were like "no not really" and so I think that } \\
\text { concerns me because it seems like even depending on which cannabis clinic certain people are referred to, } \\
\text { they are not necessarily being presented with both the pros and the cons. (MC010) }\end{array}$ \\
\hline
\end{tabular}




\section{cmaJOPEN}

Research

Table 2 (part 2 of 2): Participant quotes supporting thematic analysis

Theme/subtheme Representative quote(s)

Lack of knowledge surrounding medical cannabis

Inadequate training l'd say my knowledge of [medical cannabis] is pretty average ... average enough to know that I would refer someone else to [authorize] medical cannabis if I thought it would help. And also enough to say that it won't help with your kind of pain or your set of conditions. So, I would know enough about that, but in terms of dosing and things like that I am not as comfortable, but it's not something I sought to really train in. (MC002) I went to medical school 35 years ago, there was zero training about cannabis and anything I learned about cannabis has been through continuing education that consists of online courses and information, position statements and summaries, sessions at conferences... So, the training has been whatever I chose to participate in, there's nothing required of me. (MC005)

We did have some lectures from physicians in residency, [and] we also read a few articles during that time as well. I definitely don't know all of the up-to-date research that's ongoing in marijuana, it's just the things that I'm coming across. (MC007)

Continuing education I just don't know what the regulations are in terms of how that's monitored, so my [further] education would hopefully help me figure out where I can direct patients to, sort of more, reputable sources of marijuana once it's been prescribed. (MC002)

Something that comes out from time to time, that would actually be very helpful to get updates about what's [new] with medical cannabis. (MC007)

Physician's role regarding cannabis

[Regarding medical cannabis], it is still not a prescription. A prescription includes the name of a substance, exactly what is in it, it includes a dosage, frequency, and duration. And it is dispensed by a pharmacist. None of those criteria are being fulfilled by cannabis. I am a little bit lost right now about what my form actually does for anyone. I think anyone and his dog can walk into a drug store and get whatever they want without approval from a physician. (MC004)

Pretending that marijuana/cannabis is a prescription has been a joke ... There is nothing about dosing or actual content; the traditional approach to making cannabis accessible really has just been to say this person has a medical condition and I believe this person may benefit from medical cannabis ... Right now, it's very confusing why I have any role in making cannabis accessible to anyone. Whatever I write or say on a form does not decrease the cost of it. It does not make it funded, and it still does not provide any instructions that have to be followed ... I would love to see [the] medical profession removed from the transaction completely and to make [cannabis] more like alcohol. (MC005)

Recreational v. medicinal cannabis

I'm not sure how [recreational] products are regulated and if they know how much THC or CBD is in it, so I am not sure if [using recreational cannabis for therapeutic purposes] would be a good idea. (MC003) I think it's still helpful ... being prescribed medical cannabis because a lot of people are not sure what's the best time to take it for medical reasons. I still think there's a role for medical cannabis even if recreational cannabis is approved for use now. (MC004)

Note: $\mathrm{CBD}=$ cannabidiol, $\mathrm{THC}=$ tetrahydrocannabinol

\section{Physician's role regarding medical cannabis}

Two physicians expressed frustration regarding their role with medical cannabis because of the atypical nature of the intervention and the limited impact of their involvement. Specifically, medical cannabis does not have to be dispensed by a pharmacist, authorizing cannabis does not lower the cost for patients and physicians cannot control the composition of cannabis used for therapeutic purposes. One physician thought that there was no role for the medical profession after the legalization of cannabis for recreational purposes.

\section{Recreational versus medical cannabis}

Six physicians raised the issue of how the legalization of recreational cannabis affected its therapeutic use. Ten participants felt there was merit to preserving a separate stream for medical use, given the higher likelihood of more rigorous regulation for medical cannabis. Specifically, medical cannabis products would be required to be more consistent and adhere to higher safety standards.

\section{Interpretation}

Family physicians in our study were reluctant to authorize medical cannabis because of perceptions of limited supporting evidence, uncertainty regarding clinical indications and associated harms. Those willing to consider the use of medical cannabis typically referred interested patients to clinics that focused on this therapy, but were concerned that such clinics may provide cannabis indiscriminately without comprehensive discussion of the possible benefits and harms. One participant questioned whether there remained a role for medical cannabis after the legalization of cannabis for recreational purposes, but most physicians thought that medical cannabis would likely adhere to more rigorous quality standards. This belief requires confirmation through formal study. Participants were largely supportive of both research and continuing education to inform their views on the role of medical cannabis for their patients.

Our findings are similar to other published studies that found physicians lack a consolidated perspective regarding 
whether cannabis is a medicine and have concerns regarding the limited evidence base for medical cannabis. ${ }^{17-22,29,34,35}$ Regardless, many participants stressed the importance of keeping an open mind and considering patients' values and preferences. We found that physicians had multiple concerns associated with patient use of medical cannabis. There is evidence to suggest possible effects on neurocognitive development, ${ }^{36-38}$ drug interactions (particularly among older users), ${ }^{39-42}$ exacerbation of mental illness ${ }^{43,44}$ and insufficient standards and quality of care provided through cannabis clinics. ${ }^{45,46}$ Physicians thought their training in medical cannabis was lacking, and their interest in continuing medical education in this area is consistent with other surveys. ${ }^{28,29,31,34,47-50}$ Of note, some observational data have suggested that cannabis may be substituted for prescription medication, including opioids, anxiolytics and benzodiazepines, sedatives and antidepressants; ${ }^{51,52}$ however, this issue was not raised by our participants.

One of our participants questioned whether physicians should remain involved with medical cannabis after the legalization of recreational use. The Canadian Federation of Medical Students has released a position statement calling for increased cannabis education during medical training. ${ }^{53}$ The increasing use of cannabis by Canadians suggests that family physicians may have an ongoing role in discussing medical cannabis with interested patients. ${ }^{54}$ Open discussions may promote shared decision-making and provide opportunities to assist patients in differentiating evidence from hyperbole. ${ }^{55}$

Our study highlights the importance of addressing the knowledge gaps of family physicians and their concerns surrounding medical cannabis. Research should further investigate the needs of family physicians, as well as medical students and residents, regarding cannabis education. ${ }^{34,56}$ Increased knowledge of the evidence for the benefits and harms of medical cannabis may improve physician comfort with discussing this topic with interested patients ${ }^{57-59}$ and reduce patient reliance on cannabis clinics that may not always provide impartial advice. ${ }^{9}$

\section{Limitations}

We interviewed a modest number of physicians to inform our qualitative study; however, we sampled to saturation and only stopped recruiting new participants when no additional themes emerged in our last interview. We used snowball sampling to recruit physicians, which is prone to sampling bias, ${ }^{60}$ and we only captured the views of physicians practising in urban settings. Few of our participants authorized medical cannabis, and physicians against authorizing medical cannabis may have been overly represented in our sample. Participants may have censored their answers to appear as "good participants" (i.e., social desirability bias); however, many physicians we spoke with were forthcoming regarding their concerns about medical cannabis. Furthermore, no members of our study team had any motivation to encourage positive or negative answers. We did not implement member checking to verify our findings. To ensure the trustworthiness and rigour of our study results, 2 members of our team who are familiar with qualitative research methods conducted open coding and theme generalization, independently and in duplicate.

\section{Conclusion}

Family physicians in our study were uncertain of the therapeutic potential of medical cannabis. The exception was the use of medical cannabis for chronic pain, particularly neuropathic pain, for which all participants thought the evidence supported effectiveness. Most physicians did not provide therapeutic cannabis to their patients and expressed uncertainty regarding its harms and appropriate use. Family physicians may benefit from guidance and education that address concerns they have surrounding medical cannabis.

\section{References}

1. Cannabis for medical purposes under the Cannabis Act: information and improvements. Ottawa: Health Canada; modified 2020 July 9. Available: www. canada.ca/en/health-canada/services/drugs-medication/cannabis/medical-use -cannabis.html (accessed 2020 Nov. 9).

2. Cannabis Act (S.C. 2018, c. 16).

3. Medical document authorizing the use of cannabis for medical purposes. Ottawa: Health Canada; modified 2018 June 6. Available: www.canada.ca/en/ health-canada/services/drugs-medication/cannabis/licensed-producers/sample -medical-document-marihuana-medical-purposes-regulations.html (accessed 2020 Nov. 16).

4. Data on cannabis for medical purposes. Ottawa: Health Canada; modified 2020 Dec. 18. Available: www.canada.ca/en/health-canada/services/drugs-medication /cannabis/research-data/medical-purpose.html (accessed 2020 Nov. 16).

5. Rogin J. Her Majesty the Queen v. F.P. (a young person). Court File No. 03-CR-00002.

6. R. v. Long, 2007 ONCJ 340 (CanLII). Available: www.canlii.org/en/on/oncj/ doc/2007/2007oncj340/2007oncj340.html (accessed 2020 Nov. 16).

7. Her Majesty the Queen v. Owen Edward Smith, 2015 SCC 34, [2015] 2 S.C.R. 602.

8. Israel S. Medical marijuana middlemen: how specialty clinics cash in on legal prescriptions. CBC News 2017 Apr. 17. Available: www.cbc.ca/news/business/ medical-marijuana-prescription-clinics-1.4086351 (accessed 2020 Nov. 16).

9. Kahan M, Srivastava A, Clarke S. Cannabis industry and medical cannabis clinics need regulation. Can Fam Physician 2019;65:864-8.

10. Canadian marijuana industry snapshot. Lakewood (CO): Marijuana Business Daily; 2017. Available: https://mjbizdaily.com/wp-content/uploads/2017/11/ CanadaReportFINAL.pdf (accessed 2020 Nov. 16).

11. Lashley K, Pollock TG. Waiting to inhale: reducing stigma in the medical cannabis industry. Adm Sci Q 2020;65:434-82.

12. Grinspoon P. Older adults and medical marijuana: reduced stigma and increased use [blog]. Harvard Health Publishing, Harvard Medical School; 2020 Apr. 1, updated 2020 Apr. 6. Available: www.health.harvard.edu/blog /older-adults-and-medical-marijuana-reduced-stigma-and-increased-use-2 -2020040119321 (accessed 2020 Nov. 16).

13. Aranda AM, Conti R, Wezel FC. Distinct but not apart? Stigma reduction and cross-industry evaluative spillovers: the case of medical marijuana legalization. Acad Manage 72020 Aug. 10 [Epub ahead of print]. doi: 10.5465/amj.2018.1460.

14. Medical marijuana clinics: cannabis coverage. Available: www.marijuanamedinfo. $\mathrm{ca} /$ clinics/ (accessed 2020 Nov. 16).

15. Market data under the Access to Cannabis for Medical Purposes Regulations. Ottawa: Health Canada; modified 2019 Aug. 29. Available: www.canada.ca/en/ health-canada/services/drugs-medication/cannabis/licensed-producers/market -data.html (accessed 2020 Nov. 16).

16. Information for bealth care professionals: cannabis (maribuana, marijuana) and the cannabinoids. Ottawa: Health Canada; modified 2018 Oct. 12. Available: www. canada.ca/en/health-canada/services/drugs-medication/cannabis/information -medical-practitioners/information-health-care-professionals-cannabis -cannabinoids.html\#chp71 (accessed 2020 Aug. 5).

17. Allan MG, Finley CR, Hauptman R, et al. Missing 'high' quality evidence for medical cannabinoids for pain? Edmonton: Alberta College of Family Physicians; 2017.

18. Boehnke KF, Gangopadhyay S, Clauw DJ, et al. Qualifying conditions of medical cannabis license holders in the United States. Health Aff (Millwood) 2019;38:295-302.

19. National Academies of Sciences, Engineering, and Medicine; Health and Medicine Division; Board on Population Health and Public Health Practice; Committee on the Health Effects of Marijuana: an evidence review and research agenda. The bealth effects of cannabis and cannabinoids: the current state of evidence and recommendations for research. Washington (DC): National Academies Press (US); 2017.

20. NICE guideline [NG144]: cannabis-based medicinal products. London (UK): National Institute for Health and Care Excellence; 2019. Available: www.nice. org.uk/guidance/ng144 (accessed 2020 Nov. 16).

21. CMA policy on medical marijuana. Ottawa: Canadian Medical Association (CMA). Available: www.cma.ca/cma-policy-medical-marijuana (accessed 2020 Nov. 9). 
22. Sandelowski M. What's in a name? Qualitative description revisited. Res Nurs Health 2010;33:77-84.

23. Vaismoradi $M$, Turunen $H$, Bondas T. Content analysis and thematic analysis: implications for conducting a qualitative descriptive study. Nurs Health Sci 2013;15:398-405.

24. Tong A, Sainsbury P, Craig J. Consolidated criteria for reporting qualitative research (COREQ): a 32-item checklist for interviews and focus groups. Int 7 Qual Health Care 2007;19:349-57.

25. Miles MB, Huberman AM. An expanded sourcebook: qualitative data analysis. 2nd ed. Sage Publications; 1994.

26. Ando H, Cousins R, Young C. Achieving saturation in thematic analysis: development and refinement of a codebook. Compr Psychol 2014;3. doi: 10.2466/03.CP.3.4.

27. McGrath C, Palmgren PJ, Liljedahl M. Twelve tips for conducting qualitative research interviews. Med Teach 2019;41:1002-6.

28. Zolotov Y, Vulfsons S, Zarhin D, et al. Medical cannabis: An oxymoron? Physicians' perceptions of medical cannabis. Int F Drug Policy 2018;57:4-10.

29. Islam DA. Investigating the clinical decision-making process of physicians in rural Ontario: the perspective and attitudes on medical cannabis [thesis]. Guelph (ON): University of Guelph; 2019:1-137.

30. Zolotov Y, Vulfsons S, Zarhin D, et al. Medical cannabis: An oxymoron? Physicians' perceptions of medical cannabis. Int 7 Drug Policy 2018;57:4-10.

31. Braun IM, Meyer FL, Gagne JJ, et al. Experts' perspectives on the role of medical marijuana in oncology: a semistructured interview study. Psychooncology 2017;26:1087-92

32. Braun V, Clarke V. Using thematic analysis in psychology. Qual Res Psychol 2006;3:77-101.

33. Hayes N. Doing psychological research: gathering and analysing data. London (UK): Open University Press; 2000.

34. Shahi A, Allain S, Turner S, et al. Cannabis therapy knowledge study: toward establishing a pedagogical tool. University of Ottawa Fournal of Medicine 2018;8:19-22.

35. Szaflarski M, McGoldrick P, Currens L, et al. Attitudes and knowledge about cannabis and cannabis-based therapies among US neurologists, nurses, and pharmacists. Epilepsy Behav 2020;109:107102.

36. Lubman DI, Cheetham A, Yücel M. Cannabis and adolescent brain development. Pharmacol Ther 2015;148:1-16.

37. Bossong MG, Niesink RJM. Adolescent brain maturation, the endogenous cannabinoid system and the neurobiology of cannabis-induced schizophrenia. Prog Neurobiol 2010;92:370-85.

38. Camchong J, Lim KO, Kumra S. Adverse effects of cannabis on adolescent brain development: a longitudinal study. Cereb Cortex 2017;27:1922-30.

39. MacCallum CA, Russo EB. Practical considerations in medical cannabis administration and dosing. Eur 7 Intern Med 2018;49:12-9.

40. Abuhasira R, Schleider LB-L, Mechoulam R, et al. Epidemiological characteristics, safety and efficacy of medical cannabis in the elderly. Eur 7 Intern Med 2018;49:44-50.

41. Brown JD, Winterstein AG. Potential adverse drug events and drug-drug interactions with medical and consumer cannabidiol (CBD) use. 7 Clin Med 2019;8:989.

42. Antoniou T, Bodkin J, Ho JM-W. Drug interactions with cannabinoids. CMA7 2020;192:E206.

43. Lowe DJE, Sasiadek JD, Coles AS, et al. Cannabis and mental illness: a review. Eur Arch Psychiatry Clin Neurosci 2019;269:107-20.

44. Hill KP. Cannabis use and risk for substance use disorders and mood or anxiety disorders. FAMA 2017;317:1070-1.

45. Lucas P, Walsh Z. Medical cannabis access, use, and substitution for prescription opioids and other substances: a survey of authorized medical cannabis patients. Int 7 Drug Policy 2017;42:30-5.

46. Fitzcharles M-A, Shir Y, Häuser W. Medical cannabis: strengthening evidence in the face of hype and public pressure. CMA7 2019;191:E907-8.

47. Sagy I, Peleg-Sagy T, Barski L, et al. Ethical issues in medical cannabis use. Eur 7 Intern Med 2018;49:20-2.

48. St Pierre M, Matthews L, Walsh Z. Cannabis education needs assessment among Canadian physicians-in-training. Complement Ther Med 2020;49: 102328.

49. Karanges EA, Suraev A, Elias N, et al. Knowledge and attitudes of Australian general practitioners towards medicinal cannabis: a cross-sectional survey. BM7 Open 2018;8:e22101.

50. Ziemianski D, Capler R, Tekanoff R, et al. Cannabis in medicine: a national educational needs assessment among Canadian physicians. BMC Med Educ $2015 ; 15: 52$.
51. Corroon JM Jr, Mischley LK, Sexton M. Cannabis as a substitute for prescription drugs: a cross-sectional study. 7 Pain Res 2017;10:989-98.

52. Piper BJ, DeKeuster RM, Beals ML, et al. Substitution of medical cannabis for pharmaceutical agents for pain, anxiety, and sleep. 7 Psychopharmacol 2017;31:569-75.

53. Hartman M, Lasry D, Khan AU, et al. Canadian Federation of Medical Students position statement on recreational cannabis legalization. Ottawa: Canadian Federation of Medical Students; 2018.

54. Ng JY, Garber A, Luong M, et al. No improvement in disclosure of natural health product use to primary care medical doctors in the last 15 years: a survey of naturopathic patients. Complement Ther Clin Pract 2020;39:101106.

55. False claims in CBD product advertisements: the FDA crackdown. PharmOut 2019. Available: www.pharmout.net/fda-crackdowns-false-claims-cannabis -cbd-medicine-advertisements/ (accessed 2020 Aug. 5).

56. Ziemianski D, Capler R, Tekanoff R, et al. Cannabis in medicine: a national educational needs assessment among Canadian physicians. BMC Med Educ 2015;15:52.

57. Kansagara D, Morasco BJ, Iacocca MO, et al. Clinician knowledge, attitudes, and practice regarding cannabis: results from a National Veterans Health Administration survey. Pain Med 2020 Jan. 7 [Epub ahead of print]. doi: $10.1093 / \mathrm{pm} / \mathrm{pnz} 322$.

58. Zylla D, Steele G, Eklund J, et al. Oncology clinicians and the Minnesota Medical Cannabis Program: a survey on medical cannabis practice patterns, barriers to enrollment, and educational needs. Cannabis Cannabinoid Res 2018;3:195-202.

59. Philpot LM, Ebbert JO, Hurt RT. A survey of the attitudes, beliefs and knowledge about medical cannabis among primary care providers. BMC Fam Pract 2019;20:17.

60. Sedgwick P. Snowball sampling. BMF 2013;347:f7511.

Affiliations: Departments of Health Research Methods, Evidence and Impact (Ng, Gilotra, Usman, Chang, Busse) and Anesthesia (Busse), Faculty of Health Sciences, McMaster University; The Chronic Pain Centre of Excellence for Canadian Veterans (Busse); The Michael G. DeGroote Centre for Medicinal Cannabis Research (Busse), McMaster University, Hamilton, Ont.

Contributors: Jeremy $\mathrm{Ng}$ and Jason Busse conceptualized and designed the study. Jeremy $\mathrm{Ng}$, Kevin Gilotra, Sana Usman and Yaping Chang collected the data, which Jeremy Ng, Yaping Chang and Jason Busse analyzed. Jeremy $\mathrm{Ng}$ drafted the manuscript, which all authors critically revised. All authors approved the final version of the work to be published and agreed to be accountable for all aspects of the work.

Funding: Jeremy Ng was funded by a Research Scholarship and Entrance Scholarship from the Department of Health Research Methods, Evidence and Impact, Faculty of Health Sciences at McMaster University.

Content licence: This is an Open Access article distributed in accordance with the terms of the Creative Commons Attribution (CC BY-NCND 4.0) licence, which permits use, distribution and reproduction in any medium, provided that the original publication is properly cited, the use is noncommercial (i.e., research or educational use), and no modifications or adaptations are made. See: https://creativecommons.org/licenses/ by-nc-nd/4.0/

Data sharing: The authors have no further data to share beyond what is provided in the manuscript and appendix files.

Disclaimer: No members of the study team have used medical cannabis or have any financial or intellectual conflicts of interest in this area.

Acknowledgement: The authors gratefully acknowledge Dr. Nghi Phan for assistance in identifying study participants and reviewing the interview guide.

Supplemental information: For reviewer comments and the original submission of this manuscript, please see www.cmajopen.ca/content/9/2/ E342/suppl/DC1. 